\title{
Intra-arterial Thrombolysis of Embolic Middle Cerebral Artery Using Collateral Pathways
}

\author{
Max K. Kole, David M. Pelz, Donald H. Lee, Vivek Jain, J. David Spence, \\ Stephen P. Lownie
}

\begin{abstract}
Background and purpose: Cervical internal carotid artery (ICA) occlusion associated with middle cerebral artery (MCA) embolic occlusion requires prompt revascularization to prevent devastating stroke. With the advent of endovascular techniques for chemical and mechanical thrombolysis, the clinical outcome of patients with major arterial occlusions will improve. Finding the most expedient pathway to the site of end organ occlusion for thrombolysis is important. Methods: We present two cases of acute stroke secondary to thrombotic occlusion of the cervical ICA associated with MCA embolic occlusion treated with intra-arterial thrombolysis via catheter navigation through the posterior communicating artery to the site of MCA arterial occlusion. No attempt was made to transverse the occluded ICA. Results: Near complete restoration of flow was achieved in one patient and minimal vessel reopening was observed in the other patient. Both patients had good outcomes. Conclusion: Intraarterial thrombolysis via Circle of Willis collaterals such as the posterior communicating artery for the treatment of acute thrombotic occlusion of the cervical internal carotid artery associated with embolic occlusion of the middle cerebral artery is a therapeutic option. This treatment option avoids the potential complications of navigating through an occluded proximal internal carotid artery and may expedite reopening of the MCA.
\end{abstract}

RÉSUMÉ: Thrombolyse intra-artérielle d'une embolie de l'artère cérébrale moyenne par une voie d'accès collatérale. Introduction et but: Il faut recourir rapidement à la revascularisation dans les cas d'occlusion de la carotide interne $(\mathrm{CI})$ associée à l'occlusion embolique de l'artère cérébrale moyenne (ACM) pour éviter un accident vasculaire cérébral dévastateur. L'issue clinique des patients atteints d'occlusions artérielles majeures s'améliore depuis l'avènement des techniques endovasculaires de thrombolyse chimique et mécanique. Il est important de trouver la voie la plus avantageuse pour accéder au lieu de l'occlusion et procéder à la thrombolyse. Méthodes: Nous présentons deux cas d'accident vasculaire cérébral secondaire à une occlusion thrombotique de la CI associée à une occlusion embolique de l'ACM qui ont été traités par thrombolyse intra-artérielle, le cathéter ayant été guidé jusqu'au lieu de l'occlusion en passant par l'artère communicante postérieure. Il n'y a pas eu de tentative pour franchir l'occlusion sur la CI. Résultats: Le flot sanguin a été rétabli presque complètement chez un patient et de façon minimale chez l'autre. L'issue a été favorable chez les deux patients. Conclusions: La thrombolyse intraartérielle par les collatérales de l'hexagone de Willis, telle l'artère communicante postérieure, dans le traitement de l'occlusion thrombotique aiguë de la carotide interne associée à l'occlusion embolique de l'artère cérébrale moyenne est une option thérapeutique qui évite les complications potentielles liées au passage du cathéter par la carotide interne occluse et peut hâter l'ouverture de l'ACM.

Can. J. Neurol. Sci. 2005; 32: 257-260

Cervical internal carotid artery (ICA) occlusion associated with middle cerebral artery (MCA) embolic occlusion usually results in devastating stroke and poor patient outcome. ${ }^{1-4}$ The Prolyse in Acute Cerebral Thromboembolism Trial II represented the first randomized controlled trial that demonstrated the usefulness of local fibrinolysis in achieving better outcomes in patients with MCA occlusions. ${ }^{5}$ However, there is currently no clear consensus on the endovascular
From the Department of Clinical Neurological Sciences, (MKK, VJ, JDS, SPL); Department of Diagnostic Radiology and Nuclear Medicine, (DMP, DHL); University of Western Ontario, London Health Sciences Centre, University Campus, London, Ontario, Canada.

ReCEIVED 23 ApriL, 2004. ACCEPTED IN FINAL FORM OCTOBER 20, 2004. Reprint requests to: David M. Pelz, Department of Diagnostic Radiology, University of Western Ontario, London Health Sciences Centre, 339 Windermere Road, London, Ontario, N6A 5A5 Canada. 


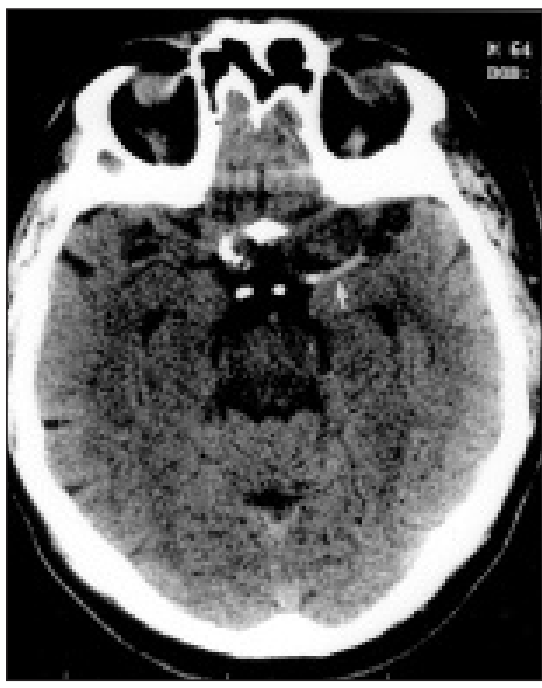

Figure 1: Commputed Tomography demonstrates a hyperdense left MCA sign. (small white arrow)

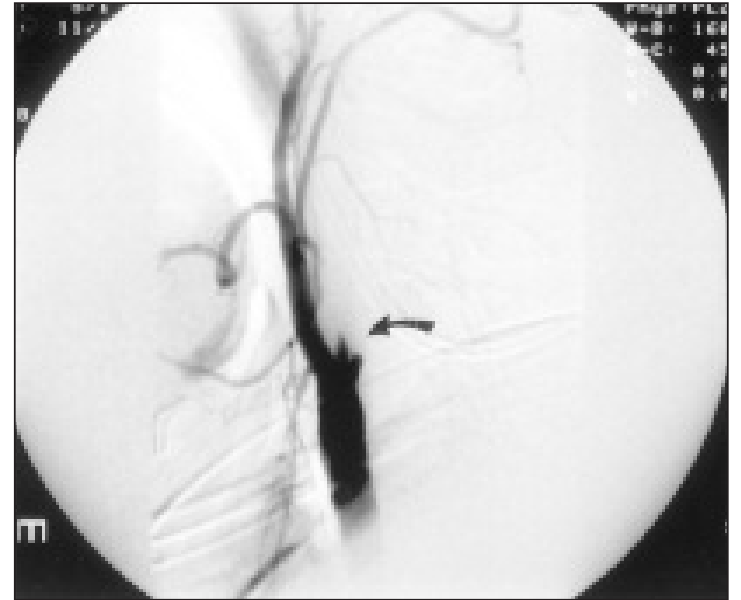

Figure 2: The left common carotid artery injection demonstrates complete occlusion of the left ICA in the neck with an irregular stump. (curved black arrow) management of acute ischemic stroke secondary to large vessel occlusion. The best thrombolytic agent, the optimum combination of mechanical and chemical thrombolysis needed, and the most expedient pathway to the site of arterial occlusion are yet to be determined.

Cervical ICA occlusion has been considered to be an obstacle to intracranial catheter navigation and thrombolytic therapy. ${ }^{1,2}$ Most neurointerventionalists recommend catheter navigation through the occluded cervical carotid artery with or without angioplasty and stenting. 1,2,4,6-8 This commonly used approach, while often successful at allowing access to the middle cerebral artery, can be time consuming and there are potential complications. We present two patients with acute, embolic MCA occlusion in association with occluded cervical ICAs, treated by intra-arterial thrombolysis via the posterior communicating artery collateral pathway. To the best of our knowledge, only one prior example of the use of collateral channels for intracranial thrombolysis has been reported. ${ }^{9}$

\section{Methods:}

\section{Case Report 1}

This 64-year-old, right-handed, retired radiologist developed the acute onset of aphasia and severe right-sided hemiparesis, (National Institutes of Health Stroke Scale Score, (NIHSS) 21). He presented to our emergency department within one hour of this event, and a computed tomogram head scan demonstrated a dense left MCA sign (Figure 1). He was treated with $8.7 \mathrm{mg}$ intravenous recombinant tissue plasminogen activator (rtPA). He was then taken to the angiography suite for possible intra-arterial thrombolysis.

The left common carotid artery injection demonstrated complete occlusion of the left ICA in the neck with an irregular stump (Figure 2), and there was no filling of the MCA territory. The right common carotid artery injection revealed a chronic complete occlusion of the right ICA in the neck. The right vertebral artery injection showed bilateral opacification of the posterior communicating arteries that supplied both internal carotid arteries. The left MCA M1 segment was occluded (Figure 3).

After demonstration of the MCA occlusion on the left, a 6-French guide catheter was placed in the right vertebral artery. Using a coaxial technique, a Micro-softstream (Boston Scientific/Target Therapeutics) microcatheter was negotiated into the basilar artery, and then forward through the posterior communicating artery into the supraclinoid ICA on the left. Superselective injection in the left ICA confirmed the left MCA thrombus with a meniscus seen medially in the vessel (Figure 4). The catheter was then advanced using a Transend (Boston Scientific/Target Therapeutics) 0.014 microguidewire into the distal M1 segment and

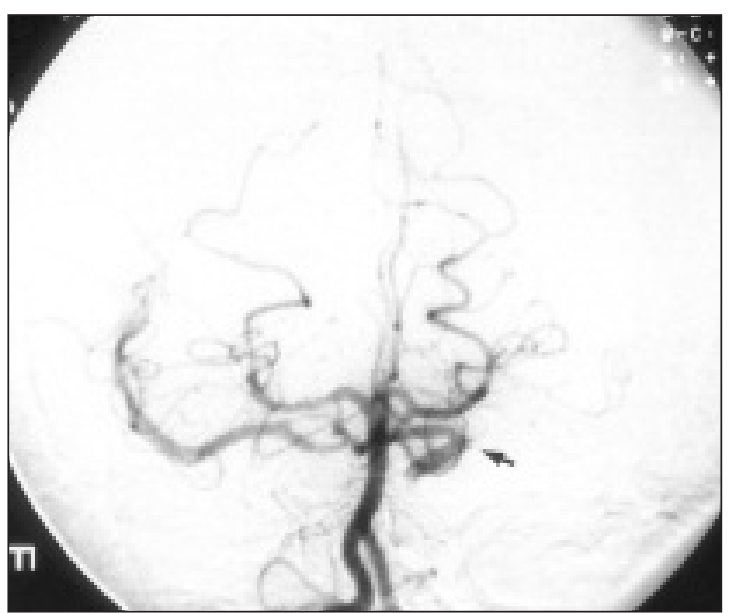

Figure 3: The right vertebral artery injection shows bilateral opacification of the posterior communicating arteries that supply both internal carotid arteries. The left MCA M1 segment is occluded. (small black arrow) 


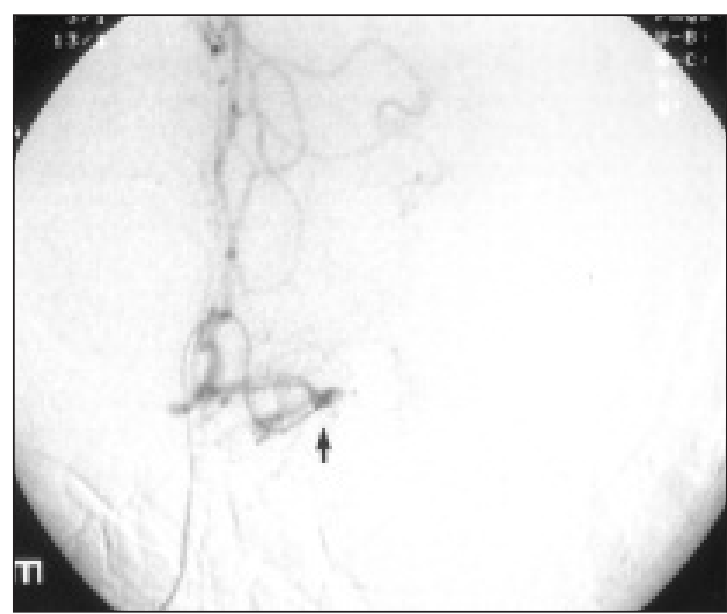

Figure 4: Superselective injection in the left ICA via microcatheter navigation through the posterior communicating artery confirms the left MCA thrombus with a meniscus seen medially in the vessel. (small black arrow)

chemical thrombolysis with rtPA was performed. Bolus injections of rtPA were carried out until a total of $15 \mathrm{mg}$ had been administered plus $3 \mathrm{mg}$ of rtPA as a continuous infusion over ten minutes. Significant flow improvement (modified-thrombolysis in myocardial infarction, (TIMI 3) was achieved in the left M1 segment and in the distal branches (Figure 5).

The patient remained systemically heparinized overnight and on the following morning, he had marked improvement of his speech and strength on the right. Magnetic resonance imaging of the brain 24 hours post thrombolysis showed diffusion abnormalities in the left frontal operculum and insula. Cerebral angiography five days post thrombolysis demonstrated recanalization of the previously occluded carotid artery in the neck. There was trickle flow through a severe stenosis. The left MCA territory remained open. The patient was taken to the operating room for a left carotid endarterectomy which was uncomplicated, and he was discharged with a near complete recovery (NIHSS $<4$ ).

\section{Case Report 2}

This 70-year-old, right-handed man, with a history of hypercholesterolemia presented approximately four hours after the acute onset of left-sided weakness, NIHSS 15 . Computed tomography demonstrated a hyperdense MCA sign, some early loss of the insular ribbon and poor definition of the lentiform nucleus on the right. He received $7 \mathrm{mg}$ of intravenous rtPA and was brought to the angiography suite.

The right common carotid artery injection demonstrated complete ICA occlusion with an irregular stump at the bifurcation in the neck. The left common carotid artery injection showed no collateral supply to the right hemisphere through the anterior communicating artery. The right vertebral artery injection opacified a large right posterior communicating artery, and a filling defect in the supraclinoid right ICA. The right MCA was completely occluded. Collateral flow to the right hemisphere was via pial collaterals from the anterior cerebral artery and the posterior cerebral artery. Intra-arterial thrombolysis using a Micro-softstream microcatheter introduced coaxially through a 6-French guide catheter placed in the right vertebral artery was performed. A Transend 0.014 microguide wire was advanced into the basilar artery, right P1 segment, right posterior communicating artery, and then into the supraclinoid right

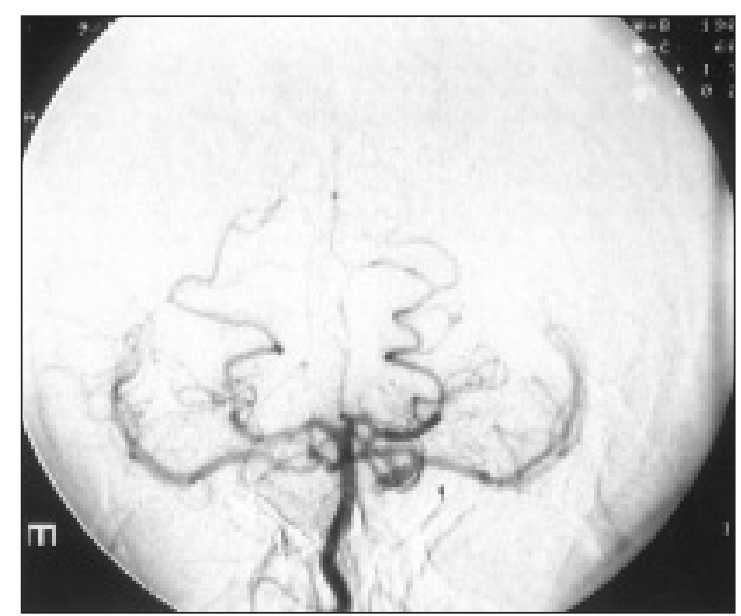

Figure 5: The right vertebral artery injection demonstrates significant flow improvement (modified-Thrombolysis in Myocardial Infarction, TIMI 3) in the left M1 segment and in the distal branches. (small black arrow)
ICA. The guide wire could not be passed beyond the right ICA bifurcation, and the microcatheter could not be advanced beyond the origin of the right posterior communicating artery from the right P1 segment. A total of $4 \mathrm{mg}$ of rtPA was injected from this position. Minimal to no recanalization was achieved (modified TIMI 1).

Over the next day, the patient demonstrated clinical improvement of his dense left hemiparesis. An MRI of the brain revealed only deep perforator diffusion abnormalities with small areas of hemorrhagic transformation. Follow-up cerebral angiography demonstrated recanalization of the right ICA associated with a severe focal stenosis at the bifurcation. In addition, the right MCA had reopened. Because of the risk of further thromboembolic events from this recanalized highly stenotic cervical carotid artery, a carotid endarterectomy was performed. The patient made a remarkable recovery and was discharged with a NIHSS of 3.

\section{DisCUSSION}

Cerebral infarction results from emboli or propagation of clot into the intracranial circulation. The critical problem is not the occlusion of the cervical ICA or the thrombus that remains in that vessel, but the intracranial embolus. ${ }^{10}$ The status of the deep perforators to the brain or end organ such as the lenticulostriate arteries determines the outcome and the length of time for rescue. ${ }^{10}$ The use of collateral pathways to gain access to the site of arterial occlusion in the MCA, as illustrated in this report, emphasizes this important concept. Spending time thrombolysing, or aspirating thrombus in the proximal ICA and then stenting the proximal ICA while infarction of the distal territory continues to evolve may not be the optimal treatment. Finding the quickest way to brain tissue at risk should be the goal of therapy. The cervical ICA occlusion can often be asymptomatic or temporary, as in our two cases. The cervical ICA can contain a large volume of thrombus and if more thrombus enters the intracranial circulation it may be more difficult to re-establish distal blood flow. ${ }^{11}$ 
Traversing an occluded vascular segment has been performed with success in peripheral vessels, in coronary arteries, as well as in proximal cervical ICA occlusion accompanied by distal MCA territory emboli. ${ }^{7}$ Traversing an occluded ICA is likely the best initial strategy, but may be time consuming and risky. Blind wire and catheter manipulation in an occluded vessel may lead to vessel perforation or dissection. Crossing an atheromatous stenosis also has the potential for time consuming wire and catheter manipulation leading to further atheroemboli. Balloon angioplasty and stenting also take time to perform, during which brain may be infarcting.

The operator should first attempt to traverse the occluded cervical internal carotid artery with a microcatheter to reach the intracranial embolus, ${ }^{2,4}$ but if this is not immediately successful, we advocate using the Circle of Willis collaterals, preferably via the anterior communicating artery or, if not possible as in our two cases, via the posterior circulation. Circle of Willis collaterals are not always present and spending an inordinate amount of time trying to navigate through the anterior or posterior communicating artery is not recommended and may be equally risky. Use of the posterior circulation, as in our cases, carries the risks of dissection and embolic stroke. Although accessing the posterior collateral route in our two patients was relatively straightforward, this may not be the case in many elderly patients. Circuitous anterior or posterior collateral pathways, via the anterior or posterior communicating arteries, may also preclude aggressive mechanial thrombolysis using guidewires, snares, and microcatheters, as occurred in our Case $2 .{ }^{12}$

Only after the intracranial arterial occlusion is opened should attention be drawn to the more proximal occlusion. In both our clinical examples, the acute cervical carotid occlusions were left alone. Thrombolysis was directed at the MCA occlusions. In one case, thrombolysis was successful through the posterior communicating artery. In the second case, navigation through the posterior communicating artery into the site of MCA arterial occlusion could not be accomplished. Within days both patients spontaneously recanalized their cervical carotid arteries. High grade stenoses were present in both patients and successful carotid endarterectomies were then performed.

The doses of rtPA used in our patients may initially not have been optimal. Two recent reports of the use of combined intravenous (IV) and intra-arterial rtPA in acute MCA stroke ${ }^{13,14}$ recommend initiation of full dose IV therapy within three hours of the event, followed by up to $20 \mathrm{mg}$ of intra-arterial rtPA, to a maximum of $82 \mathrm{mg}$. Patient 1 required only a total of $27 \mathrm{mg}$, to recanalize the MCA. Patient 2 received only a small dose of IV rtPA due to his presentation at four hours after his event, and only $4 \mathrm{mg}$ IA rtPA due to the relatively unstable catheter position in the posterior communicating artery.

There are no standardized treatment guidelines for intraarterial thrombolysis and no consensus exists on the technical methods for achieving recanalization. However, time plays a critical factor in patient outcome. This technical report illustrates an alternative, potentially faster pathway to the site of arterial occlusion via the posterior communicating artery.

\section{REFERENCES}

1. Spearman MP, Jungreis CA, Wechsler LR. Angioplasty of the occluded carotid artery. AJNR Am J Neuroradiol 1995; 16: 17911796.

2. Endo S, Kuwayama N, Hirashima Y, et al. Results of urgent thrombolysis in patients with major stroke and atherothrombotic occlusion of the cervical carotid artery. AJNR Am J Neuroradiol 1998; 19: 1169-1175.

3. Rabinstein AA, Wijdicks EFM, Nichols DA. Complete recovery after early intra-arterial recombinant tissue plasminogen activator thrombolyis of carotid T occlusion. AJNR Am J Neuroradiol 2002; 23: 1596-1599.

4. Komiyama M, Nishio A, Nishijima Y. Endovascular treatment of acute thrombotic occlusion of the cervical internal carotid artery associated with embolic occlussion of the middle cerebral artery: case report. Neurosurgery 1994; 34:359-364.

5. Furlan A, Higashida R, Wechsler L, et al. Intra-arterial prourokinase for acute ischemic stroke. The PROACT II study: a randomized controlled trial. Prolyse in acute cerebral thromboembolism. JAMA 1999; 282(21): 2003-2011.

6. Connors III JJ, Wojak JC. Specific stroke situations, territories, and guidelines for therapy. In: Connors III JJ, Wojak JC (Eds). Interventional Neuroradiology: Strategies and Practical Techniques. W.B. Saunders Company, Philadelphia, PA 1999: 692-751.

7. Nesbit GM, Clark WM, O'Neill OR, Barnwell SL. Intracranial intra-arterial thrombolysis facilitated by microcatheter navigation through an occluded cervical internal carotid artery. J Neurosurg 1996; 84: 387-392.

8. Burnette WC, Nesbit GM, Barnwell SL. Intra-arterial thrombolysis for acute stroke. In: Nesbit GM (Eds). Neuroimaging Clinics of North America. W.B. Saunders Company, Philadelphia, PA 1999: 9: 491-508.

9. Restrepo L, Pradilla G, Llinas R, Beauchamp NJ. Perfusion- and diffusion-weighted MR imaging-guided therapy of vertebral artery dissection: intra-arterial thrombolysis through an occipital vertebral anastomosis. AJNR Am J Neuroradiol 2003; 24: 18231826.

10. Adams HP, Adams RJ, Brott T, et al. Guidelines for the early management of patients with ischemic stroke. A scientific statement from the Stroke Council of the American Stroke Association. Stroke 2003; 34: 1056-1083.

11. Lutsep HL, Clark WM, Nesbit GM, Kuether TA, Barnwell SL. Intra-arterial suction thrombectomy in acute stroke. AJNR Am J Neuroradiol 2002; 23(5): 783-786.

12. Qureshi AI, Siddiqui Am, Suri MF, et al. Aggressive mechanical clot disruption and low-dose intra-arterial third-generation thrombolytic agent for ischemic stroke: a prospective study. Neurosurgery 2002; 51: 1319-1329.

13. Hill MD, Barber PA, Demchuk AM, et al. Acute intravenous-intraarterial revascularization therapy for severe ischemic stroke. Stroke 2002; 33: 279-282.

14. The IMS Study Investigators. Combined intravenous and intraarterial recanalization for acute ischemic stroke: the Interventional Management of Stroke Study. Stroke 2004; 35: 904-912. 